\title{
Descentralização do Licenciamento Ambiental em Minas Gerais
}

Decentralization of Environmental Licensing In Minas Gerais

Descentralización de licencias ambientales en Minas Gerais

Mariana Lasmar Marques da Silva

Engenheira Ambiental e Sanitarista, UFLA, Brasil marianalmsilva@gmail.com

\section{Luís Antônio Coimbra Borges}

Professor Doutor, UFLA, Brasil. luis.borges@ufla.br 


\section{RESUMO}

O Licenciamento Ambiental é um dos instrumentos da Política Nacional do Meio Ambiente necessário para toda atividade com potencial de gerar dano ao meio ambiente. No Brasil, o licenciamento era exercido prioritariamente pela União e pelos Estados, porém com os crescentes pedidos de licença no país, a descentralização do licenciamento é uma alternativa para atender a está demanda, passando também essa competência para a esfera municipal, visando maior agilidade no processo de obtenção destas licenças. $O$ objetivo deste trabalho foi analisar a situação do processo de descentralização do licenciamento ambiental no Estado de Minas Gerais. A metodologia seguiu uma abordagem qualitativa, a coleta de dados ocorreu por meio de revisão de literatura e documental, e uso de questionário semiestruturado enviado a todos os municípios de Minas Gerais que possuem convênio firmado com o Estado para realização do licenciamento municipal. Como resultado, averiguou-se que sete municípios possuem convênio com o Estado para realizarem o licenciamento municipal e foram constatadas as peculiaridades que cada município passou durante a adoção do processo local de licenciamento. Conclui-se que Minas Gerais encontra-se atrasado no processo de municipalização, e que esta atribuição é muito importante para o município adquirir autonomia e promover seu desenvolvimento sustentável.

PALAVRAS-CHAVE: Municipalização. Licenciamento municipal. Impacto local.

\section{ABSTRACT}

Environmental licensing is one of the instruments of the National Environmental Policy necessary for any development that may cause damage to the environment. In Brazil, licensing has being carried out primarily by the federal government and by the states, but with the increasing requests for licenses, decentralization is an alternative to deal with the high demand also passing this competence to the municipal sphere aiming for greater agility in the process of these licenses. The purpose of this paper was to analyze the current situation of the environmental licensing decentralization process in the State of Minas Gerais. The methodology followed a qualitative approach, the data collection was done through a literature and documentary review, and also through the use of a semi-structured questionnaire sent to all municipalities of Minas Gerais that have an agreement signed with the State for municipal licensing. As a result, it was verified that seven municipalities have an agreement with the State to execute the municipal licensing and was also verified the peculiarities that each municipality passed during the adoption of the local licensing. It was concluded that the State of Minas Gerais is behind in the descentralization process, and that this attribution it is really important for the municipality to acquire autonomy and promote its sustainable development.

KEYWORDS: Municipalization; Municipal Licensing; Local Impact.

\section{RESUMEN}

La Licencia Ambiental es uno de los instrumentos de la Política Ambiental Nacional necesaria para cualquier actividad con el potencial de generar daños al medio ambiente. En Brasil, la concesión de licencias fue ejercida principalmente por la Unión y los Estados, sin embargo, con las crecientes solicitudes de licencias en el país, la descentralización de las licencias es una alternativa para satisfacer esta demanda, pasando también esta competencia a la esfera municipal, con el objetivo de una mayor agilidad en el proceso de obtención de estas licencias. El objetivo de este trabajo fue analizar la situación del proceso de descentralización de las licencias ambientales en el estado de Minas Gerais. La metodología siguió un enfoque cualitativo, la recolección de datos se realizó a través de la literatura y la revisión documental, y el uso de un cuestionario semiestructurado enviado a todos los municipios de Minas Gerais que tienen un acuerdo firmado con el Estado para llevar a cabo las licencias municipales. Como resultado, se descubrió que siete municipios tienen un acuerdo con el Estado para llevar a cabo las licencias municipales y se encontraron las peculiaridades que cada municipio experimentó durante la adopción del proceso de licencias locales. Se concluye que Minas Gerais se está quedando atrás en el proceso de municipalización, y que esta atribución es muy importante para que el municipio adquiera autonomía y promueva su desarrollo sostenible.

PALABRAS CLAVE: Municipalización Licencias municipales. Impacto local. 


\section{INTRODUÇÃO}

Nas últimas décadas a degradação ambiental vêm se intensificando e se tornando insustentável para a capacidade de absorção da terra. Em vista disso, houve um aumento na conscientização ambiental sendo criadas novas leis com o objetivo de conscientizar a população sobre a importância da preservação do meio ambiente.

Nesse sentido, em 1981, foi instituída a Lei Federal n 6.938 que consolida a Política Nacional do Meio Ambiente (PNMA) com o intuito de preservar e recuperar a qualidade ambiental propícia à vida.

Visando minimizar as consequências causadas pelas ações antrópicas no meio ambiente, a PNMA estabelece os instrumentos de gestão ambiental. A partir de medidas preventivas, estes instrumentos têm por objetivo regulamentar atividades que possuem potencial para causar impactos sobre o meio ambiente, podendo ser compreendidos como restrições de atividades, especificação de tecnologias e controle do uso de recursos naturais (BARROS, 2012). Dentre estes instrumentos, o licenciamento ambiental é um dos mais importantes da política ambiental, dado que o mesmo tem a finalidade de garantir que os recursos naturais estejam disponíveis às gerações futuras (RODRIGUES, 2010; VIEIRA JÚNIOR; PASQUALETTO, 2011; SANJUAN, 2007).

De maneira geral, o licenciamento tem como objetivo fundamental tornar os empreendimentos que possam causar degradação no meio ambiente mais viáveis no ponto de vista ambiental por meio da análise sobre a viabilidade ambiental das atividades econômicas, assegurando que estas se instalem em locais ambientalmente adequados e adotem tecnologias que minimizem os possíveis impactos negativos sobre o ambiente (MONTAÑO et al. 2007).

A Resolução CONAMA n 237/1997, responsável por regulamentar o licenciamento ambiental, prevê três tipos de licenças que podem ser expedidas pelo poder público. São estas: a Licença Prévia (LP), Licença de Instalação (LI) e Licença de Operação (LO). De acordo com as características do empreendimento, estas licenças podem ser expedidas isoladas ou concomitantemente.

No que diz respeito a competência para realizar o licenciamento, a Resolução CONAMA $n^{\circ}$ 237/97, estabelece que as licenças sejam emitidas conforme a área de influência ou a grandeza do impacto do empreendimento, podendo ser de responsabilidade da União, ou do Estado, ou Distrito Federal ou do Município (VIEIRA JÚNIOR;PASQUALETTO, 2011). A divisão entre os entes federativos obedece ao princípio da predominância de interesse, onde será responsabilidade da União os assuntos de interesse nacional, dos Estados os de interesses regionais e dos Municípios os de interesse local (CHIESA, 2009).

No entanto, nos últimos anos, esta competência tem sido exercida de forma centralizada principalmente pelos órgãos federais e estaduais e, considerando as dimensões continentais do país, a gestão ambiental centralizada mostrou- se incapaz de propiciar real proteção ao meio ambiente (RIBAS et al, 2013). A fim de regulamentar a cooperação entre os três níveis de governo, no que se refere a defesa do meio ambiente, foi instituída a Lei Complementar $n^{\circ}$ 140/2011 (NASCIMENTO; FONSECA, 2016).

Baseando-se na Lei Complementar $n^{\circ}$ 140/2011, os Estados passaram a delegar aos municípios 
a competência sobre o licenciamento de atividades com impactos locais. Visto que a instância municipal é a mais apropriada para lidar com problemas locais, o processo de descentralização ou municipalização do licenciamento ambiental possibilita um controle territorial de maior qualidade através de uma gestão ambiental mais eficaz (AGNES et al, 2009; CHIESA, 2009; ESCOBAR, 2011).

Em Minas Gerais, a municipalização do licenciamento ambiental está consolidada na Lei Estadual $n^{\circ} 21.972 / 2016$, a qual traz que o processo de licenciamento e a fiscalização ambiental de empreendimentos que possam causar degradação ao meio ambiente, podem ser delegados aos Municípios pelo Estado, e pelo Decreto Estadual $n^{\circ} 46.937 / 2016$ o qual estabelece que, os municípios que estejam de acordo com a estrutura de gestão ambiental proposta no próprio Decreto, estarão aptos a celebrar com o Estado de Minas Gerais, através da SEMAD, convênio de cooperação técnica e administrativa tendo como objetivo o licenciamento e a fiscalização ambiental de empreendimentos com impactos ambientais restritos aos limites do município (MINAS GERAIS, 2016b).

Conforme mencionado, para que os municípios assumam o licenciamento, deve ser respeitado alguns critérios estabelecidos na legislação estadual, tais como: o município deve contar com uma política municipal de meio ambiente, um conselho de meio ambiente, órgão técnicoadministrativo na estrutura do Poder Executivo Municipal, onde o corpo técnico possua qualificação mínima, e um sistema de fiscalização ambiental legalmente estabelecido. É neste sentido, que o convênio a ser firmado entre os entes municipais e o estadual é de grande importância, já que o mesmo tem a finalidade de atestar que o município atende aos requisitos básicos para assumir o licenciamento (MINAS GERAIS, 2016b; NASCIMENTO;FONSECA, 2016).

Com o intuito de atender a Lei Complementar $n^{\circ}$ 140/2011 e estabelecer as tipologias de empreendimentos dos quais o licenciamento ambiental será atribuição dos Municípios, foi instituída a Deliberação Normativa COPAM n ${ }^{\circ}$ 213/2017.

Dessa forma, será competência do município realizar o licenciamento, controle e fiscalização ambiental de empreendimentos, que simultaneamente, estejam enquadrados nas tipologias listadas no Anexo Único da DN COPAM n²13/2017, possuam sua Área Diretamente Afetada (ADA) e Área de Influência Direta (AID) dentro dos limites territoriais do município e sejam enquadradas nas classes 1 a 4 da DN COPAM n² 217/2017 (SEMAD, 2017).

\section{OBJETIVO GERAL}

Analisar o processo de descentralização do licenciamento ambiental que está sendo implantado no Estado de Minas Gerais, buscando identificar as peculiaridades em cada município que aderiu ao licenciamento ambiental municipal.

\section{Objetivos específicos}

Identificar os municípios que aderiram ao convênio até o ano de 2017 e aplicar questionário semiestruturado a estes municípios a fim de compreender como ocorreu o processo, comparar a descentralização no Estado de Minas Gerais com demais Estados do Brasil e analisar a evolução deste processo entre o ano de 2017 e início de 2020. 


\section{METOdOLOGIA}

Para a produção do trabalho foi realizada a coleta de dados por meio de pesquisa documental (documentos e legislações), revisão de literatura e uso de questionário semiestruturado.

O estudo utilizou metodologia com abordagem qualitativa que, segundo Sanjuan (2007), possibilita uma investigação mais detalhada sobre comportamentos e tendências. Este método de pesquisa é apropriado por se tratar de um estudo exploratório, que visa buscar o aprendizado sobre tema que ainda não tenha sido muito pesquisado "descentralização do licenciamento ambiental" - e construção de um entendimento baseado nas ideias dos participantes que irão responder o questionário do pesquisador (ABREU, 2016; CRESWELL,2010).

A revisão de literatura e documental do presente estudo foi fundamentada na análise dos mecanismos que incidem sobre o licenciamento ambiental e que influenciam a municipalização deste processo. A revisão de literatura consistiu em consultas a dissertações, artigos, teses e livros relacionados ao objeto de estudo, com o intuito de compreender como se encontra a atual situação da municipalização no Estado de Minas Gerais.

A análise documental foi baseada na legislação ambiental vigente. Nesta análise, foram pesquisados os conteúdos das leis e políticas, que dispõe sobre o licenciamento ambiental, em âmbito federal e estadual, e também foram consultados os convênios, responsáveis por regulamentar a municipalização, firmados entre o Estado e os Municípios que aderiram ao licenciamento ambiental municipal.

O questionário semiestruturado poderá contribuir com a caracterização do processo de municipalização do licenciamento ambiental buscando dados primários, dado que existem poucos dados secundários disponíveis ao público (ABREU, 2016). Para isso, foi elaborado um questionário que abrangeu os aspectos específicos sobre a descentralização em cada município mineiro, visto que, devido as diferenças regionais, este processo ocorre de maneira dessemelhante em cada região.

As perguntas foram elaboradas com o intuito de compreender o porque dos municípios aderirem a este novo sistema, quais foram as dificuldades para a implantação do mesmo, buscar informações sobre como o processo de licenciamento está sendo realizado no município e por fim, conhecer os profissionais envolvidos em todo o processo. O questionário foi enviado aos municípios com competência para o licenciamento ambiental municipal que possuem convênio firmado com o Estado de Minas Gerais. O questionário aplicado é apresentado no Quadro 1. 
Quadro 1: Questionário aplicado aos municípios habilitados ao licenciamento.

\begin{tabular}{|c|l|}
\hline $\mathbf{N}^{\circ}$ & \multicolumn{1}{|c|}{ Pergunta } \\
\hline 1 & Porque o município optou pela municipalização do licenciamento ambiental? \\
\hline 2 & Quais foram as principais dificuldades encontradas durante o processo de municipalização? \\
\hline 3 & $\begin{array}{l}\text { O modelo de licenciamento municipal segue o modelo adotado nas esferas estadual e federal? Quais } \\
\text { modalidades de licença são emitidas pelo município? }\end{array}$ \\
\hline 4 & O município possui legislação ambiental municipal que trata sobre o licenciamento? \\
\hline 5 & $\begin{array}{l}\text { Considerando que a documentação tenha sido registrada corretamente, qual é o tempo médio de emissão } \\
\text { das licenças? }\end{array}$ \\
\hline 6 & Quantos processos foram protocolados e licenciados desde a municipalização do licenciamento? \\
\hline 7 & Os técnicos responsáveis pelo licenciamento são concursados? \\
\hline 8 & Quais as formações profissionais dos técnicos envolvidos no processo? \\
\hline 9 & Eles recebem capacitação para atuar no processo de licenciamento municipal? \\
\hline
\end{tabular}

Após o levantamento, os dados coletados foram analisados e descritos a fim de executar as análises quali-quantitativas e confecção de gráficos representativos para a elaboração dos resultados finais.

\section{RESULTADOS E DISCUSSÃO}

\subsection{MUNICÍPIOS COM LICENCIAMENTO MUNICIPAL}

Dentre os 853 municípios do Estado de Minas Gerais, segundo a SEMAD (2017), no ano de 2017, somente sete desses municípios possuíam convênio firmado com o Estado para a realização do processo de licenciamento. Os municípios que possuem este convênio são: Belo Horizonte, Betim, Brumadinho, Contagem, Juiz de Fora, Ibirité e Uberaba. Sendo assim, não mais que $0,82 \%$ dos municípios estavam habilitados a realizar o licenciamento ambiental municipalizado (FIGURA 1).

Ainda de acordo com a SEMAD, no ano de 2017, todos os municípios do Estado receberam o ofício circular SURAM SEMAD no 30/2017, com solicitação formal para adesão ao licenciamento ambiental municipal, e como resposta o órgão obteve a manifestação de competência originária de 23 municípios, sendo eles: Araporã, Belo Vale, Barbacena, Carmo do Cajuru, Extrema, Felixlândia, Frutal, Itabira, Itabirito, Itajubá, Malacacheta, Mariana, Montes Claros, Muriaé, Pará de Minas, Patrocínio, Pompéu, Ribeirão das Neves, Sacramento, Santa Luzia, Três Marias e Tupaciguara. Portanto, dentre o total de 853 municípios mineiros, apenas 2,58\% apresentaram manifestação para adesão ao processo municipal de licenciamento ambiental (FIGURA 1). 
Figura 1:Taxa de municípios habilitados ao licenciamento ambiental em 2017.

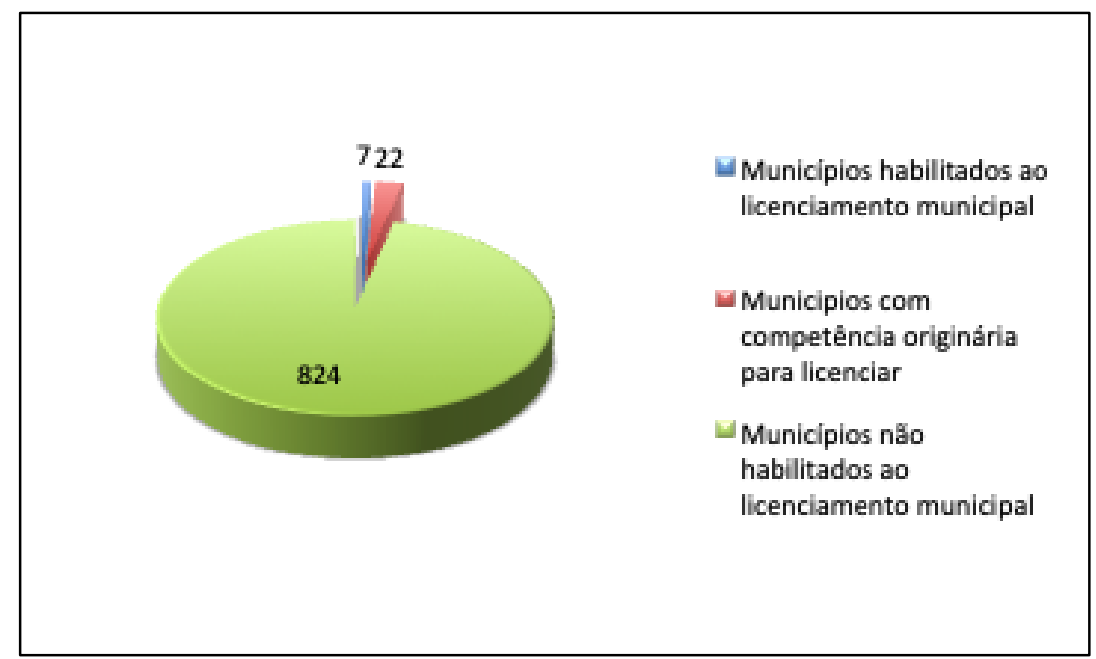

Fonte: Do Autor (2018).

\subsection{COMPARATIVO COM OUTROS ESTADOS}

Quando comparado com os outros Estados da Região Sudeste, Minas Gerais é o que apresenta o menor número de municípios habilitados a licenciar, como pode ser observado na Figura 2.

Figura 2:Municípios habilitados ao licenciamento ambiental na Região Sudeste.

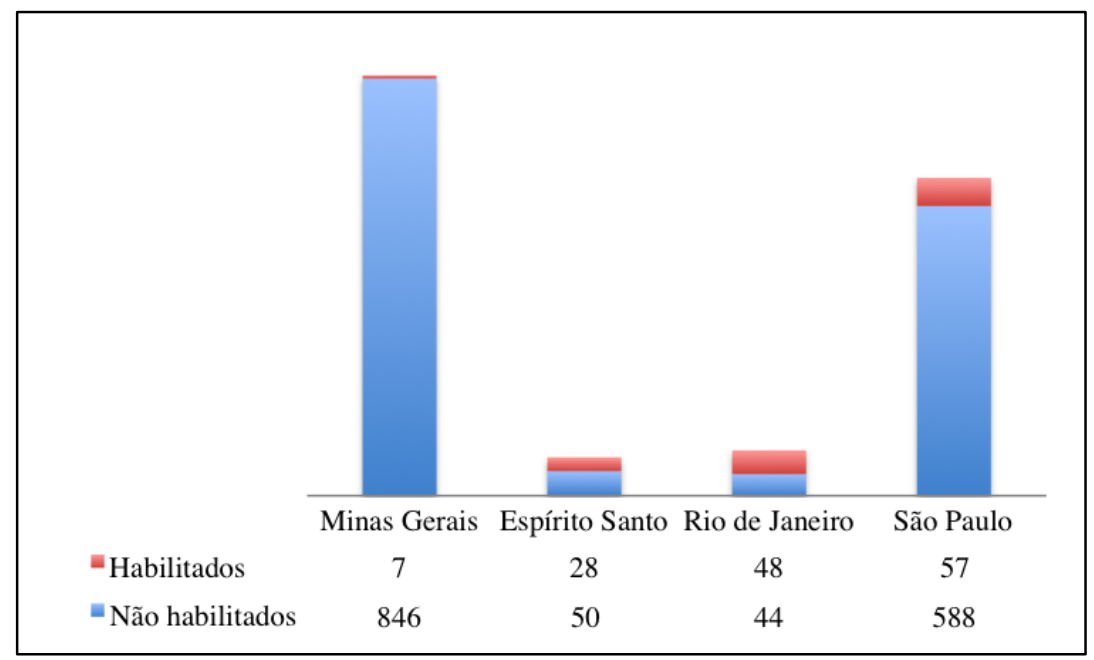

Fonte: Do Autor (2018). 
Ainda observando a Figura 2, foi possível perceber a discrepância na quantidade de municípios habilitados no Estado de São Paulo, o segundo maior da região considerando o número de cidades, com a quantidade de municípios mineiros aptos a realizarem seu próprio licenciamento. Enquanto São Paulo possui 57 municípios descentralizados, o que representa $8,8 \%$ do total de 645 municípios do estado, Minas Gerais possui apenas sete habilitados, não atingindo nem $1 \%$ do total de municípios do estado. Este atraso pode ser atribuído ao fato de que $77,96 \%$ do território de Minas Gerais corresponde a municípios com uma população menor que 20.000 habitantes, que não possuem estrutura de gestão ambiental adequada, conforme estabelecido pelo Decreto Estadual $n^{\circ} 46.937 / 16$, para assumir a competência do licenciamento ambiental.

\subsection{RESULTADO DO QUESTIONÁRIO APLICADO AOS MUNICÍPIOS}

O questionário foi enviado aos sete municípios que, em 2017, já possuíam convênio firmado com o Estado, mas apenas quatro municípios responderam, sendo eles: Betim, Brumadinho, Ibirité e Juiz de Fora.

A municipalização do licenciamento ambiental em Minas Gerais ainda se encontra em um estágio inicial, mas através do questionário aplicado pôde ser constatado que no geral os municípios que optaram por exercer o licenciamento visam dar maior independência ao governo municipal em relação ao Estado, e obter um controle maior sobre as atividades em seu território, tendo em vista também, o desenvolvimento econômico municipal, além de obter uma eficácia maior no controle ambiental.

O município de Betim, que possui muitas empresas de cunho industrial, optou por realizar o licenciamento ambiental local, pois este é de suma importância para promover a eficiência administrativa na concessão de licenças ambientais e como resultado desta agilidade, promover um maior desenvolvimento econômico, além de facilitar o monitoramento do controle ambiental das atividades.

Brumadinho adotou o processo de descentralização a fim de melhorar a qualidade ambiental e ainda, criar uma projeção do município no panorama estadual do licenciamento, gerar maior autonomia ao município para resolver assuntos de interesse local e dessa forma cooperar com o sistema de licenciamento estadual e melhorar a participação popular e desenvolver a economia local através da movimentação de empresas ligadas ao negócio ambiental e atração de investimentos e empreendimentos.

No caso de Ibirité, o licenciamento ambiental municipal foi adotado devido às particularidades da região que seriam melhor atendidas pelo corpo técnico multidisciplinar capacitado presente no município, além dessa razão, tem- se a questão de um melhor controle junto ao município dos impactos locais e dos principais problemas ambientais.

Partindo do pressuposto que cada município possui sua peculiaridade, presume- se que cada um deles passou pelo processo de municipalização de uma maneira diferente, porém de maneira semelhante, todos enfrentaram dificuldades ao longo do processo. A maior dificuldade que esses municípios encontraram foi a elaboração de normas regulamentares, ou seja, a 
criação de uma legislação ambiental local. Os municípios de Minas Gerais não foram os únicos a se depararem com este entrave, segundo Ribas et al (2013), o principal obstáculo encontrado pelos municípios recém habilitados do Rio Grande do Sul, também foi a criação de uma legislação especifica regulamentando o licenciamento ambiental. Além disso, cada município passou por distintos obstáculos até atingirem o licenciamento municipalizado eficaz.

A principal dificuldade para a cidade de Betim, foi a realização de concursos públicos e a organização do sistema de gestão ambiental, já que ambos dependem da vontade política dos gestores. Brumadinho teve como dificuldade a falta de suporte e orientação do Estado, enquanto, Ibirité teve problemas com os empreendimentos localizados no território do município relacionado a aceitação dos mesmos ao licenciamento ambiental. Juiz de Fora, além da dificuldade na estruturação do órgão ambiental, também passou por dificuldades durante a contratação de analista e capacitação técnica.

Todos os municípios entrevistados seguem o modelo de licenciamento ambiental adotado pela esfera estadual, sendo assim a classificação dos empreendimentos são baseadas na DN COPAM $n^{\circ}$ 217/2017. Segundo Nascimento e Fonseca (2016), as licenças mais expedidas nos municípios descentralizados do Brasil, são as Licenças Prévias, Licenças de Instalação e Licenças de Operação e seguindo este padrão, como pode ser observado na Figura 3, os quatro municípios entrevistados emitem estas licenças, comprovando que os mesmos seguem o modelo trifásico adotado pelo Estado.

Figura 3: Modalidade de licenças emitidas pelos municípios estudados.

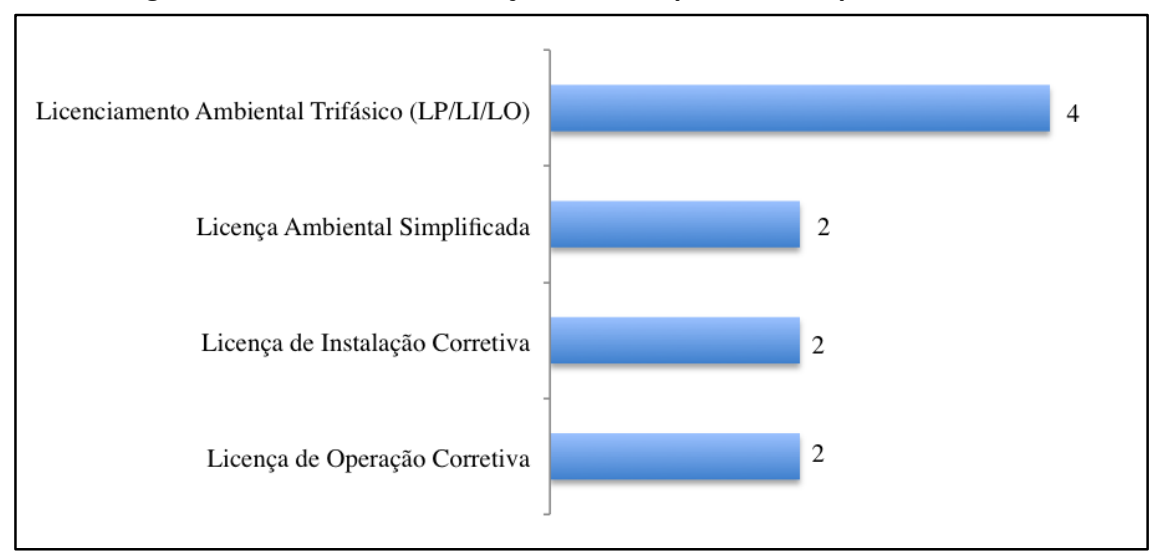

Fonte: Do autor (2018).

Conforme análise da Figura 3, apenas dois municípios emitem a LAS, sendo eles: Juiz de Fora e Brumadinho. Assim como a LAS, apenas dois municípios emitem a Licença de Instalação Corretiva (LIC) e Licença de Operação Corretiva (LOC), sendo eles Ibirité e Brumadinho.

Além das Licenças descritas na Figura 3, o município de Brumadinho também expede as seguintes modalidades: Licença de Operação para Pesquisa Mineral e Autorização Provisória para Operar e o município Juiz de Fora emite também, o Certificado de Conformidade Ambiental.

A respeito da legislação ambiental municipal relacionada ao licenciamento ambiental, todos os municípios afirmaram possuir alguma lei que trata do assunto sendo que cada município possui uma legislação específica sobre o licenciamento. 
A Lei Ambiental Municipal $n^{\circ}$ 3.274/1999 do município de Betim, dispõe sobre a política de proteção do meio ambiente e melhoria da qualidade de vida no município, esta lei é regulamentada pelo Decreto Municipal n $16.660 / 2001$. A referida lei é responsável por regular o licenciamento ambiental, trazendo o mesmo como um instrumento de gestão e regulação ambiental onde, é de responsabilidade do órgão executivo municipal de meio ambiente deliberar sobre o licenciamento de empreendimentos de pequeno porte, enquanto os empreendimentos de médio e grande porte são de responsabilidade do CODEMA.

A Lei Complementar n 067/2012 do município de Brumadinho dispõe sobre a Política Municipal de Meio Ambiente, e ainda, o municípios possui uma segunda legislação ambiental, a DN CODEMA n] 04/2013.

O município de Ibirité possui a Lei Complementar $n^{\circ} 80 / 2008$, que trata da política de proteção do meio ambiente e melhoria da qualidade de vida no município, porém esta lei não possui regulamento e por isso, será revogada pelo Código Ambiental Municipal, o qual está sendo elaborado e entrará em vigor no ano de 2018, até este entrar em vigência está sendo utilizada a legislação Estadual.

O município de Juiz de Fora possui regulamento para licenciamento de hospitais, no que se refere a gestão de resíduos, sendo este a DN COMDEMA $n^{\circ}$ 35/2008 que dispõe sobre normas para o licenciamento ambiental de estabelecimentos geradores de resíduos de serviços de saúde, possui também, a DN COMDEMA $n^{\circ} 30 / 2007$ que estipula as normas para o licenciamento de atividades minerárias, DN COMDEMA $n^{\circ}$ 26/2006 responsável por estabelecer as normas para o licenciamento de estações de telecomunicações, DN COMDEMA $n^{\circ} 42 / 2012$ dispõe sobre as normas ara o licenciamento para atividade movimentação de terra, o procedimento para licenciamento ambiental de loteamentos é estabelecido pela DN COMDEMA $n^{\circ}$ 04/2001, e por fim, possui a DN COMDEMA n $14 / 2003$ que dispõe sobre o Licenciamento Ambiental Simplificado.

O tempo médio de emissão das licenças varia de acordo com o município e com o tipo do empreendimento. No município de Betim o processo de licenciamento é feito no máximo na metade do prazo legal, sendo que o prazo legal é de 90 dias para as classes 1 e 2, e 180 dias para as classes 3 e 4 .

No município de Ibirité, todas as modalidades de licença devem passar pelo CODEMA e como este conselho possui reuniões mensais o prazo de emissão pode variar de 30 a 60 dias.

Brumadinho possui um prazo de emissão de 90 dias que esta estabelecido na Lei Complementar $n^{\circ}$ 067/2012, mas este prazo pode variar devido a necessidade de informações complementares aos estudos apresentados.

O tempo médio para o município de Juiz de Fora é de seis meses, sendo o prazo de emissão mais longo dentre os municípios estudados.

De acordo com o Diagnóstico da Municipalização do Meio Ambiente no Brasil, o processo de licenciamento quando realizado pelos municípios possui um tempo médio de 25 dias, com as resposta obtidas, pode- se concluir que todos os municípios estudados ultrapassam este prazo médio de emissão. 
Os municípios também foram questionados sobre o número de processos protocolados e licenciados desde que ocorreu a municipalização do licenciamento, mas apenas os municípios de Ibirité e Brumadinho souberam informar sobre este ponto. Na cidade de Ibirité, a média de processos abertos é de cinco por mês, enquanto apenas três licenças são emitidas por mês. No munícipio de Brumadinho, desde que este assumiu a competência para o licenciamento, foram protocolados 406 processos e foram licenciados apenas 51, ou seja $12,56 \%$ destes processos. Apesar do município de Betim não saber ao certo a quantidade de processos protocolados, foi informado pelo mesmo que nem todos os processos protocolados estão sujeitos ao licenciamento ambiental, ou seja, muitos destes são dispensados da licença ambiental.

Em relação aos técnicos que são responsáveis pelo processo de licenciamento nos municípios, foi questionado se estes seriam concursados e sobre a formação dos mesmos. Todos os municípios entrevistados possuem técnicos concursados, mas parte dos profissionais envolvidos no processo são contratados como foi ressaltado pelos municípios de Betim, Brumadinho e Ibirité.

O concurso é importante pois traz independência para o técnico na análise dos processos de licenciamento, evitando intervenção política no ato de licenciar, sendo isto um entrave encontrado por Nascimento Júnior e Pasqualetto (2011), além de evitar a alta rotatividade dentro do quadro de funcionários, que como foi apontado por Abreu (2016), esta pode causar atrasos nos processos desenvolvidos pelo órgão ambiental.

Segundo Nascimento Júnior e Pasqualetto (2011), seria mais eficaz para o licenciamento ambiental do município se no quadro de técnicos envolvidos no processo estiver presente, no mínimo, um geólogo, biólogo, engenheiro ambiental ou agrônomo ou florestal, engenheiro civil, sociólogo e tecnólogos. A Quadro 2 mostra a formação dos profissionais responsáveis pelo licenciamento nos municípios estudados, e como pode ser observado, existe uma grande variação na área de formação dos técnicos, estando em conformidade com o que foi proposto por Nascimento Júnior e Pasqualetto (2011). No geral, foi constatado que as áreas de formação mais presentes nos quadros de técnicos destas cidades, foram a de Biólogo, seguida pelo Engenheiro e Gestor Ambiental e Engenheiro Civil, como pode ser observado na Quadro 2. 
Quadro 2: Área de formação dos profissionais responsáveis pelo LA por município.

\begin{tabular}{|c|c|c|c|c|c|c|c|c|c|c|c|c|c|c|c|}
\hline FORMAÇÃO & 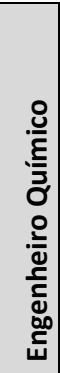 & 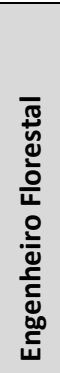 & 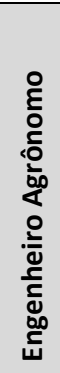 & 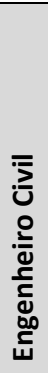 & 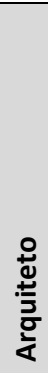 & $\frac{.0}{\frac{.0}{\Sigma}}$ & 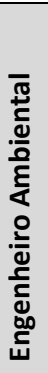 & $\begin{array}{l}\text { 음 } \\
\frac{0}{\circ} \\
\frac{0}{0}\end{array}$ & 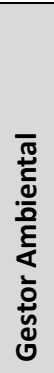 & 范 & 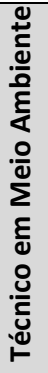 & 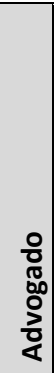 & 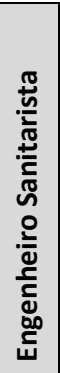 & 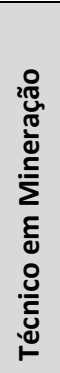 & 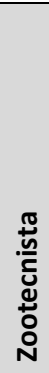 \\
\hline Betim & $x$ & $x$ & $x$ & $x$ & $x$ & $x$ & $x$ & $x$ & - & - & - & - & - & - & - \\
\hline Brumadinho & - & - & - & - & - & - & $x$ & $x$ & $x$ & $x$ & $x$ & - & - & $x$ & - \\
\hline Ibirité & - & - & $x$ & $x$ & - & - & $x$ & $x$ & $x$ & - & $x$ & $x$ & - & - & $x$ \\
\hline Juiz de Fora & $x$ & $x$ & - & $x$ & $x$ & - & - & $x$ & $x$ & $x$ & - & - & $x$ & - & - \\
\hline
\end{tabular}

Fonte: Do Autor (2018).

Relacionou-se no Quadro 2 os municípios entrevistados com os profissionais presentes no quadro de funcionários relacionados ao processo de licenciamento ambiental. O município de Juiz de Fora é o único que não conta com um Engenheiro Ambiental, sendo este profissional extremamente essencial para o processo de licenciamento ambiental, tanto na análise quanto na aprovação do licenciamento, conforme dito por Nascimento Júnior e Pasqualetto (2011), isso pode influenciar negativamente na emissão das licenças. Os demais municípios contam com um quadro de profissionais adequado para atuarem no processo de licenciamento, sem que haja restrições e limitações técnicas.

Conforme Abreu (2016), um dos pontos fracos do licenciamento ambiental municipalizado é a carência de capacitação técnica, esta falta de técnicos capacitados pode ser considerado um entrave no processo de licenciamento. De acordo com as respostas obtidas, foi possível observar que nos municípios de Betim, Ibirité e Juiz de Fora os técnicos recebem capacitação para atuarem no licenciamento ambiental municipal. É importante ressaltar que esta interação com o órgão Estadual contribui para o desenvolvimento constante dos profissionais. Apesar da grande importância desta capacitação, no município de Brumadinho os técnicos não passam por capacitação, são apenas instruídos à lerem a Legislação Ambiental Municipal.

\subsection{EVOLUÇÃO DA DESCENTRALIZAÇÃO ENTRE OS ANOS 2017 E 2020}

Segundo a lista de municípios com competência originária para licenciar disponibilizada pela SEMAD (2020), no ano de 2017, apenas 22 municípios deram início à esta atribuição, representando 2,58\% dos municípios mineiros. Atualmente, a lista conta com 99 municípios que são considerados aptos a licenciar dentro dos termos da DN COMPAM n ${ }^{\circ}$ 213/2017 e já deram inicio à competência originária emitindo as licenças para as atividades de impacto local. Portanto, dentre o total de 853 municípios, $11,61 \%$ aderiram à descentralização do licenciamento. Vale ressaltar que, estes municípios com competência originária não possuem o convênio de cooperação técnica e administrativa com o Estado. 
No que diz respeito aos municípios que celebram o convênio com o Estado, o aumento foi menos significativo. Como dito anteriormente, em 2017, sete municípios possuíam este convênio, representando $0,82 \%$ do municípios mineiro. De acordo com a lista de convênios disponibilizada pela SEMAD (2020), apenas dois municípios entraram para esta lista, sendo estes Extrema e Ponte Nova, totalizando nove municípios conveniados, representando 1,05\% dos municípios do estado.

A Figura 4 apresenta a situação atual da descentralização do licenciamento ambiental em Minas Gerais.

Figura 4:Taxa de municípios habilitados ao licenciamento ambiental em 2020.

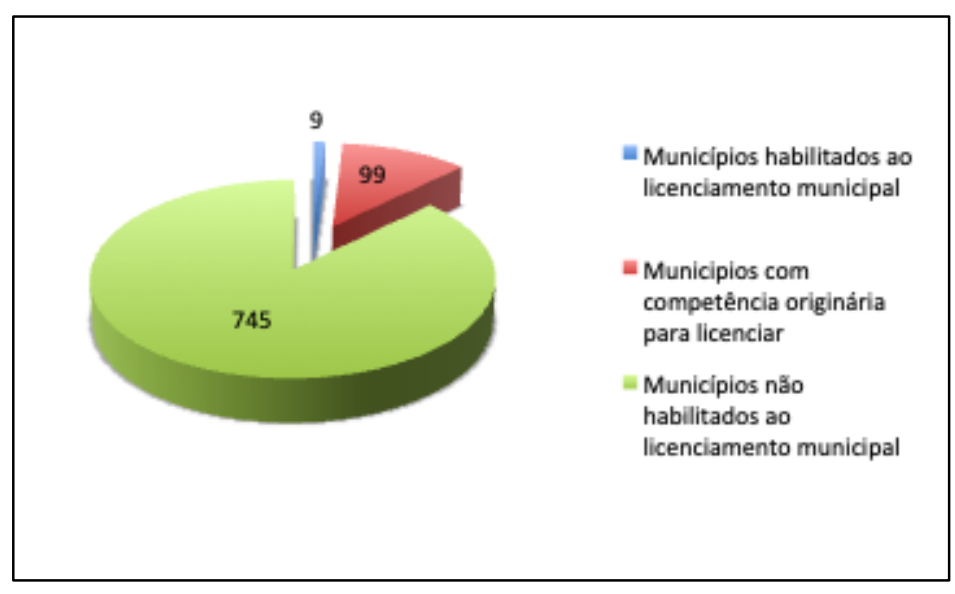

Fonte: Do Autor (2018).

\section{CONCLUSÃO}

Apesar do licenciamento municipal de atividades com impacto local ser um dever constitucional atribuído aos municípios, a descentralização no Estado encontra- se muito atrasada em relação ao restante da região Sudeste do país. Este atraso pode ser atribuído ao fato de que a maior parte do território de Minas Gerais corresponde a municípios com uma população menor que 20.000 habitantes, que não possuem estrutura de gestão ambiental adequada para assumir a competência do licenciamento ambiental municipal.

A vantagem da municipalização do processo de licenciamento é, além de diminuir o fluxo de processos analisados pelo Estado, dar aos municípios maior autonomia sobre seu território possibilitando ao mesmo maior desenvolvimento econômico e também, maior eficácia na proteção ambiental local devido à proximidade das atividades licenciadas ao órgão licenciador. Durante o processo de descentralização foram encontrados entraves, como a dificuldade na criação de uma legislação ambiental local, para se alcançar o objetivo final. Seria necessário nesse caso maior orientação do Estado para auxiliar os municípios recém habilitados a desenvolverem o programa de licenciamento ambiental municipal.

Foi possível constatar que o município de Juiz de Fora não possui um Engenheiro Ambiental em seu quadro de funcionários o que pode acarretar numa limitação técnica durante o processo de licenciamento. Outro fato que pode ocasionar carência técnica no licenciamento ambiental é a falta de capacitação dos técnicos, fato que ocorre no município de Brumadinho. 
Para o município de Betim, o licenciamento ambiental municipal é de grande importância para promover a eficiência administrativa na concessão de licenças ambientais visto que o município possui muitas empresas de cunho industrial.

Foi possível concluir que o município de Ibirité, apesar de já estar habilitado a realizar o licenciamento municipal, ainda esta em processo de construção de uma legislação ambiental municipal adequada para regular este instrumento.

Mesmo com a dificuldade de se obter informações dos municípios de Belo Horizonte, Uberaba e Contagem, foi possível concluir também que para evitar morosidade e interferência política nos processos de licenciamento ambiental, é necessário que os envolvidos no licenciamento sejam técnicos concursados, fato que ocorre apenas parcialmente nos municípios estudados. Por fim, foi possível observar que, entre os anos de 2017 e 2020, houve um pequeno aumento à adesão ao processo de descentralização mostrando que a municipalização é uma realidade porém está ocorrendo de maneira vagarosa.

\section{REFERÊNCIAS BIBLIOGRÁFICAS}

ABREU, E. L. Municipalização do licenciamento ambiental: Análise comparada de experiência nos Estados de Minas Gerais e Piauí. 2016. 117p. Dissertação (Mestrado em Engenharia Ambiental - Área de Concentração Meio Ambiente) - Universidade Federal de Ouro Preto (UFOP), Ouro Preto, 2016.

AGNES, C. C; et al. Uma discussão sobre a descentralização da gestão ambiental. Revista Científica Eletrônica de Engenharia Florestal, Garça, n. 14, p. 53-73, agosto de 2009.

BARROS, D. A; et al. Breve análise dos instrumentos da política de gestão ambiental brasileira. Política \& Sociedade, Florianópolis, v. 11, n. 22, p. 155 - 189, novembro de 2012.

BETIM. Lei no 3.274 de 20 de dezembro de 1999. Disponível em: <http://www.betim.mg.gov.br/ARQUIVOS_ANEXO/lei_3274_1999_lei_ambienal;07243110;20061128.pdf>. Acesso em: 22 de dezembro de 2017.

BRASIL. Lei n.o 6.938, de 31 de agosto de 1981. Diário Oficial da União, Poder Executivo, Brasília, DF, 2 de setembro de 1981. Seção 1, p. 16509.

BRASIL. Lei Complementar n.o 140, de 8 de dezembro de 2011. Diário Oficial da União, Poder Executivo, Brasília, DF, 12 de dezembro de 2011. Seção 1, p. 2.

CHIESA, M, A, S. Gestão ambiental: entraves e perspectivas para a municipalização no Estado do Espírito Santo. In: II CONGRESSO CONSAD DE GESTÃO PÚBLICA. Anais...Brasília: Conselho Nacional de Secretários de Estado da Administração, 2009.

CONFEDERAÇÃO NACIONAL DE MUNICÍPIOS (CNM). Diagnóstico da Municipalização do Meio Ambiente no Brasil. Brasília, 2009. 17p.

CONSELHO NACIONAL DE MEIO AMBIENTE (CONAMA). Resolução $\mathbf{n}^{\circ}$ 237/1997. Dispõe sobre a revisão e complementação dos procedimentos e critérios utilizados para o licenciamento ambiental. Disponível em:<http://www.mma.gov.br/port/conama/legiabre.cfm?codlegi=237>. Acesso em: 10 de novembro de 2017.

CRESWELL, J. W. Projeto de pesquisa: métodos qualitativo, quantitativo e misto. 2.ed. Porto Alegre: Artmed/Bookman, 2007. 247p.

ESCOBAR, M. L. As vantagens da delegação de competência do licenciamento ambiental dos estados para os municípios. Uniabeu, Belford Roxo, v. 4, n. 6, p. 182- 195, janeiro-abril de 2011. 
MINAS GERAIS. Decreto n46.937, de 21 de janeiro de 2016. Minas Gerais Diário do Executivo, 22 de janeiro de 2016b. Col. 2, p. 3.

MINAS GERAIS. Deliberação Normativa COPAM n 213 de 22 de fevereiro de 2017. Minas Gerais Diário Executivo, 24 de fevereiro de 2017a. p. 31.

MINAS GERAIS. Deliberação Normativa COPAM n 217 de 6 de dezembro de 2017. Minas Gerais Diário Executivo, 8 de dezembro de 2017b. p. 14.

MINAS GERAIS. Lei $\mathbf{n}^{\circ}$ 21.972, de 21 de janeiro de 2016. Minas Gerais Diário do Executivo, 22 de janeiro de $2016 \mathrm{~d}$. Col. 1, p. 1.

MONTAÑO, M.; OLIVEIRA, I.S.D. de; RANIERI, V.E.L.; FONTES, A.T.; SOUZA, M.P. de. O zoneamento ambiental e a sua importância para a localização de atividades. Revista Pesquisa e Desenvolvimento Engenharia de Produção, Itajubá, n. 6, p. 49- 64, 2007.

NASCIMENTO, T. R. S; FONSECA, A. Opinião de gestores e analistas ambientais sobre a municipalização do licenciamento ambiental: uma sondagem nacional. In: CONGRESSO BRASILEIRO DE AVALIAÇÃO DE IMPACTO, 2, 2016, Ribeirão Preto. Anais...Ribeirão Preto: Serviço de Biblioteca "Prof.Dr.Sérgio Rodrigues Fontes", 2016. P. 515-522.

RIBAS, A.A.; KOHLER, A.; COSTA, A. B. da. Municipalização do licenciamento ambiental no Estado do Rio Grande do Sul. Caderno de Pesquisa, Série Biologia, Santa Cruz do Sul, v. 25, n.1, p. 60-73, 2013.

RODRIGUES, G. S. S. C. A análise interdisciplinar de processos de licenciamento ambiental no Estado de Minas Gerais: conflitos entre velhos e novos paradigmas. Sociedade \& Natureza, Uberlândia, v. 22, n. 2, p. $267-282$, agosto de 2010.

RODRIGUES, M.M. Política Nacional do Meio Ambiente e a eficácia de seus instrumentos. Revista Âmbito Jurídico, Rio Grande, n.74, março de 2010.

SANJUAN, M.M.T. Caracterização dos elementos fundamentais para efetivação da municipalização do licenciamento ambiental. 2007. 168p. Dissertação (Mestrado em Engenharia Ambiental Urbana) - Universidade Federal da Bahia, Salvador, 2007.

SECRETARIA DE MEIO AMBIENTE (SMA). Legislação ambiental. Juiz de Fora, 2017. Disponível em: <https://www.pjf.mg.gov.br/secretarias/sma/legislacao/index.php>.Acesso em: 22 de dezembro de 2017.

SECRETARIA ESTADUAL DE MEIO AMBIENTE E DESENVOLVIMENTO DE MINAS GERAIS (SEMAD). Gestão Ambiental Municipal. 1 ed. Belo Horizonte, 2017. 48p.

SECRETARIA ESTADUAL DE MEIO AMBIENTE E DESENVOLVIMENTO DE MINAS GERAIS (SEMAD). Municípios conveniados.

Disponível

em:

<http://www.meioambiente.mg.gov.br/component/content/article/13informativo/2568- municipios-conveniados>. Acesso em: 16 de novembro de 2017.

SECRETARIA ESTADUAL DE MEIO AMBIENTE E DESENVOLVIMENTO DE MINAS GERAIS (SEMAD). Municípios conveniados.

Disponível

em:

<http://www.meioambiente.mg.gov.br/component/content/article/13informativo/2568- municipios-conveniados>. Acesso em: 31 de janeiro de 2020.

VIEIRA JÚNIOR, E. J; PASQUALETTO, A. Análise da descentralização do sistema de licenciamento ambiental no Estado de Goiás. 2011. 26 p. Monografia (Bacharel em Engenharia Ambiental), Pontifícia Universidade Católica de Goiás, Goiânia, 2011. 